\title{
Twelve-Week Internet-Based Individualized Exercise Program in Adults With Systemic Lupus Erythematosus: Protocol for a Randomized Controlled Trial
}

Simone Cosima Boedecker ${ }^{1 *}$, Dr med; Keito Finn Akanby Philippi ${ }^{2 *}$, MSc; Elmo Neuberger ${ }^{2}$, PhD; Sebastian Schmidt ${ }^{2}$, MSc; Daniel Pfirrmann ${ }^{2}$, PhD; Nils Haller ${ }^{2}$, PhD; Andreas Schwarting ${ }^{1}$, Prof Dr; Perikles Simon ${ }^{2}$, Prof Dr, Dr; Julia Weinmann-Menke ${ }^{1}$, Prof Dr

\footnotetext{
${ }^{1}$ Department of Rheumatology and Nephrology, University Medical Center Mainz, Mainz, Germany

${ }^{2}$ Department of Sports Medicine, Disease Prevention and Rehabilitation, Johannes Gutenberg University Mainz, Mainz, Germany

*these authors contributed equally
}

\section{Corresponding Author:}

Simone Cosima Boedecker, Dr med

Department of Rheumatology and Nephrology

University Medical Center Mainz

Langenbeckstraße 1

Mainz, 55131

Germany

Phone: 491717000996

Email: SimoneCosima.Boedecker@unimedizin-mainz.de

\begin{abstract}
Background: Systemic lupus erythematosus is a systemic autoimmune disease, which is associated with high cardiovascular risk, a predisposition to metabolic disorders, muscle wasting, and fatigue. Exercise therapy has become an important part of the long-term treatment of comorbidities in systemic lupus erythematosus. Exercise can lead to various benefits in patients with systemic lupus erythematosus such as increased aerobic capacity and exercise tolerance, resulting in an increased quality of life, decreased depression, and decreased fatigue. At the moment, no evidence-based treatment guidelines that recommend exercise for patients with systemic lupus erythematosus exist. Also, the efficacy of different training programs requires further investigation.

Objective: This study focuses on the feasibility, efficacy, and safety of an internet-based exercise program in patients with systemic lupus erythematosus. Furthermore, we investigate the feasibility and efficiency of anaerobic training compared to aerobic training.

Methods: Overall, patients with systemic lupus erythematosus from the Division of Nephrology, Rheumatology, and Immunology outpatient clinic of the University Medical Center Mainz who are clinically stable status are included and randomized in an aerobic exercise group $(n=10)$, anaerobic exercise group $(n=10)$, or treatment as usual group $(n=10)$. After completing initial clinical testing and physical fitness tests, patients undergo supervised 12-week online exercise programs, receiving weekly individualized training plans adapted to their physical performance. The primary outcome is change in physical fitness (VO2 peak) after 12 weeks compared to baseline. Secondary outcomes are disease activity measured via laboratory results (complement, autoantibodies) and questionnaires, as well as changes in muscle mass (anaerobic exercise group), results of the Chair-Stand test, and measurements of circulating cell-free DNA and extracellular vesicles.
\end{abstract}

Results: The study was registered in May 2019. Enrollment began in May 2019. Of 40 patients who were initially screened, 30 patients fulfilled the inclusion criteria and were included in the study; 1 participant withdrew prior to the start of the exercise program. Among the 25 patients who completed the study, no serious adverse events have been reported; 3 participants withdrew during the program (due to frequent colds, $n=1$; Crohn relapse, $n=1$; physical strain, $n=1$ ), and 1 participant has not yet completed the program. Data analysis is ongoing, and results are expected to be submitted for publication in January 2021.

Conclusions: We expect the online exercise intervention to be a feasible and efficient tool to provide regular individualized exercise for patients with systemic lupus erythematosus.

Trial Registration: ClinicalTrials.gov NCT03942718; http://clinicaltrials.gov/ct2/show/NCT03942718.

International Registered Report Identifier (IRRID): DERR1-10.2196/18291 
(JMIR Res Protoc 2020;9(11):e18291) doi: 10.2196/18291

\section{KEYWORDS}

systemic lupus erythematosus; physical activity; internet-based exercise program, disease activity; fatigue

\section{Introduction}

Systemic lupus erythematosus is a chronic autoimmune disease that affects organs and tissues, such as skin, kidney, joints, lungs, and the central nervous system [1]. Its etiology is still unknown. Remarkably, nearly $90 \%$ of patients with systemic lupus erythematosus are females [2]. Its incidence in Germany in 2002 was 15.4 per 100,000 in males and 55.4 per 100,000 in females [3]. Worldwide, prevalence ranges from 20 to 70 per 100,000 [4]. Both geographical and racial differences seem to influence the prevalence of systemic lupus erythematosus [4].

Therapeutic approaches aim to ensure long-term survival by keeping disease activity low, reducing drug toxicity, and improving quality of life [5-7]. Due to improved drug therapies, the 10-year survival rate of patients with systemic lupus erythematosus increased remarkably from approximately $50 \%$ in the 1950s to $>90 \%$ since 1990; however, long-term use of drugs and the inflammatory potential of the disease itself cause a host of comorbidities such as cardiovascular disease, end-stage renal failure, or osteoporosis [8]. Compared to the general population, the risk of death is still greater by approximately 5 -fold $[9,10]$. It has been shown that cardiovascular disease is the main risk factor of increased death and organ damage [11].

In addition to classical therapy options, nonpharmacological interventions, which are well tolerated by the patient, are desirable. Between $67 \%$ and $90 \%$ of patients with systemic lupus erythematosus, depending on their ethnicity, report fatigue which leads to tiredness, inactivity, and thus, to a reduction of physical fitness $[12,13]$. This often accompanies a progressive reduction of muscle mass leading to sarcopenia [14]. Therefore, the effect of exercise in patients with systemic lupus erythematosus was investigated in several small case studies [14-20], and it was shown that exercise may be a promising augment treatment to counteract the negative effects caused by inactivity in patients with systemic lupus erythematosus (ie, fatigue, depression, disease activity, sarcopenia, and reduced aerobic capacity). Several studies have shown that physical exercise is well tolerated in systemic lupus erythematosus [21]. Cycling, running, and walking were shown to be effective and well tolerated in patients with systemic lupus erythematosus
$[14,18,21,22]$, while progressive resistance training with elastic bands is considered to be a safe method to improve muscle strength [23]; however, cardiovascular training seems to have a better effect on the quality of life of patients than resistance training does [24].

While previous studies $[19,25,26]$ applied a supervised face-to-face exercise concept, which is very costly and time consuming due to a high staff load, more time- and cost-effective interventions are necessary to make this training concept accessible to as many patients as possible. Internet-based exercise interventions fulfill these requirements. Furthermore, individualized internet-based exercise programs, unlike group interventions, allow adjustments for each patient. There is also the possibility of a higher level of adherence, since patients are free to decide on which day and at what time they schedule their sports program, regardless of their different daily routines. Therefore, we developed an individualized internet-based exercise program. We hypothesized that patients will adhere to a 12-week exercise program and that the program will lead to a significant improvement in peak oxygen uptake, demonstrating an improvement in aerobic capacity, as well as a reduction of fatigue, depression, disease activity, and sarcopenia in patients with systemic lupus erythematosus.

\section{Methods}

\section{Ethics}

This study was approved by the ethics commission of the University Medical Center Mainz, Germany and the Medical Associations Rhineland-Palatinate (number 2018-13039) and conformed to the standards of the Declaration of Helsinki of the World Medical Association. Written consent was obtained from all participants at the beginning of the study.

\section{Recruitment}

Participants aged 18-65 years and diagnosed with systemic lupus erythematosus according to the 1982 American College of Rheumatology classification criteria and the new 2019 European League Against Rheumatism/American College of Rheumatology Classification Criteria were recruited [5,27]. Detailed inclusion and exclusion criteria are listed in Table 1. 
Table 1. Inclusion and exclusion criteria.

\begin{tabular}{|c|c|}
\hline Type & Criteria \\
\hline \multirow[t]{4}{*}{ Inclusion } & $\begin{array}{l}\text { 1. Diagnosis of systemic lupus erythematosus by the classification criteria } \mathrm{ACR}^{\mathrm{a}} \text { and the } 2019 \mathrm{EULAR}^{\mathrm{b}} / \mathrm{ACR} \text { Classification Criteria } \\
\text { for systemic lupus erythematosus }\end{array}$ \\
\hline & 2. Positive antinuclear antibody titer $(\geq 1: 80)$ or anti-dsDNA ${ }^{\mathrm{c}}(\geq 200 \mathrm{IU} / \mathrm{mL})$ or positive anti-dsDNA autoantibody $(\geq 30 \mathrm{IU} / \mathrm{mL})$ \\
\hline & 3. Systemic Lupus Erythematosus Disease Activity Index $\geq 4$ \\
\hline & $\begin{array}{l}\text { 4. For } 30 \text { day prior, stable immunosuppressive therapy with steroid }(0-20 \mathrm{mg} / \text { day }) \text { or other immunosuppressive medication such as } \\
\text { hydroxychloroquine, chloroquine, azathioprine, methotrexate, mycophenolate mofetil, cyclosporine, belimumab, rituximab }\end{array}$ \\
\hline \multirow[t]{3}{*}{ Exclusion } & 1. Pregnancy \\
\hline & 2. Active lupus nephritis, myocarditis, or pericarditis \\
\hline & 3. Physical activity more than 2 times a week \\
\hline
\end{tabular}

${ }^{a}$ ACR: American College of Rheumatology.

bULAR: European League Against Rheumatism.

cdsDNA: anti-double stranded DNA.

\section{Study Design}

After recruiting and screening participants $(n=30)$, they were randomized to 3 groups: mainly aerobic training $(n=10)$, mainly anaerobic training $(\mathrm{n}=10)$, and control (treatment as usual; $\mathrm{n}=10$ ). The patients in the control group have the option to participate in one of the exercise groups after 12 weeks of treatment as usual (Figure 1). By creating 2 different exercise groups, we wished to study whether there are different effect sizes and differences in feasibility. As far as we know, no data are available on anaerobic training conditions for patients with systemic lupus erythematosus.

Figure 1. Study design.

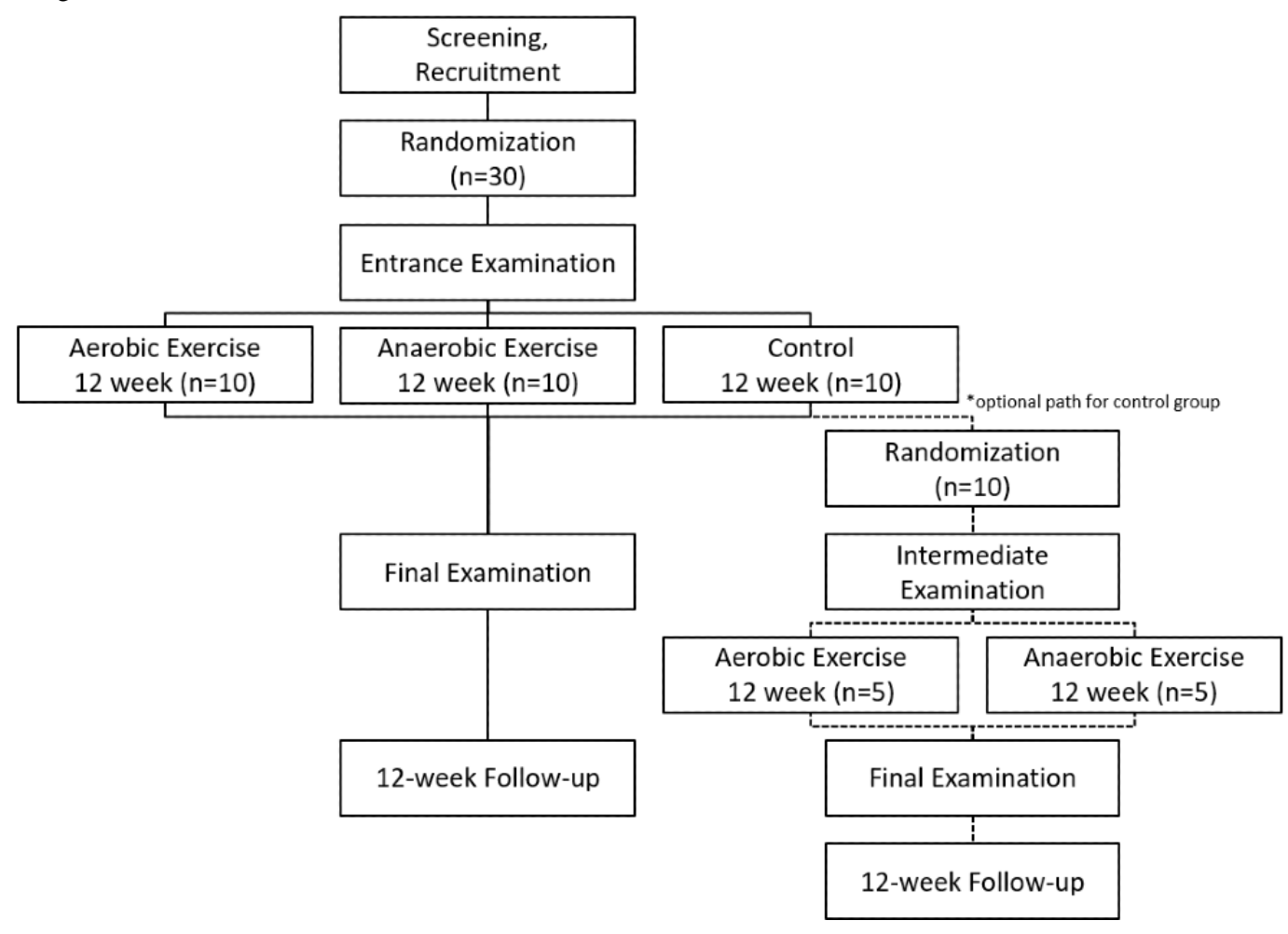

During the examinations and follow-up appointments, which take place in the Division of Nephrology and Rheumatology outpatient clinic of the University hospital Mainz and the Department of Sports Medicine of the University in Mainz, blood samples are taken, and questionnaires are filled out. During the outpatient visits, the patients are cared for by the study doctor and a doctoral student in sport medicine. Participants undergo preliminary examination, which includes bioelectric impedance analysis (InBody 3.0, InBody Co Ltd), a Chair-Stand test (as many complete sit-stand-sit cycles as

possible, with a chair height of $43.2 \mathrm{~cm}$, in 30 seconds) [23], resting electrocardiography (ECG) (AT-60; Schiller Medizintechnik $\mathrm{GmbH}$ ), and a pulmonary function test (Bodybox 5500, Medisoft Group).

During physical fitness testing, patients undergo spiroergometry and ECG. To determine individual physical performance, participants undergo standardized stepwise exercise test on a laboratory treadmill (Saturn, H/p/cosmos Sports \& Medical $\mathrm{GmbH}$ ) until participative exhaustion, with a modified walking protocol (Table 2) that includes 14 steps of increasing velocity 
and partially increasing slope [28]. Absolute and relative contraindications as well as stop criteria to terminate spiroergometry were defined according to the guidelines [29].
The same physical fitness tests are repeated at the end of the 12-week period to evaluate the effect of the training program of each participation.

Table 2. Modified walking protocol [28].

\begin{tabular}{lllll}
\hline Stage & Time, minutes & Cumulated time, minutes & Velocity, km/h & Slope, $\%$ \\
\hline 1 & 3 & 3 & 3.0 & 1.5 \\
2 & 3 & 6 & 3.7 & 3.0 \\
3 & 3 & 9 & 4.4 & 4.9 \\
4 & 3 & 12 & 5.1 & 6.3 \\
5 & 3 & 15 & 5.8 & 7.4 \\
6 & 3 & 18 & 6.5 & 8.2 \\
7 & 3 & 21 & 6.5 & 11.4 \\
8 & 3 & 24 & 6.5 & 13.0 \\
9 & 3 & 27 & 6.5 & 14.6 \\
10 & 3 & 30 & 6.5 & 16.2 \\
11 & 3 & 33 & 6.5 & 17.8 \\
12 & 3 & 36 & 6.5 & 19.4 \\
13 & 3 & 39 & 6.5 & 21.0 \\
\hline
\end{tabular}

\section{Intervention}

After exercise testing, patients in both intervention groups were given an individual account for the internet platform. In a personal introduction appointment after exercise testing, participants received information about the internet platform and all materials, such as the smartwatch (M430, Polar Electro Oy) and 3 different resistance bands (KG 67071, 67072, 67073, Trendy Sport GmbH \& Co). The smartwatch was used to evaluate the physical strain of the patients (heart rate) and distance during exercise. Participants had the opportunity to enhance social contacts by using the smartwatch's internal message function. Training videos for home-based resistance training could be downloaded from the platform.

Every Monday, an individualized training schedule was sent to each patient in both intervention groups. Participants are given a weekly protocol, where all physical activities during the week, including all recommended (endurance and strength) and additional activities, should be recorded. After each week, a sports therapist analyzes the training data to adapt the schedule for the following week according to participant self-reported values of pain and training load (Table 3 ).

Table 3. Weekly individual training adjustment [28].

\begin{tabular}{lll}
\hline Pain $^{\mathrm{a}}$ & Load $^{\mathrm{a}}$ & Adjustment \\
\hline If & $0-6$ & Increase \\
$0-3$ & 7 & Maintain \\
$0-3$ & $8-10$ & Reduce \\
Else if & & Maintain \\
$4-6$ & $0-7$ & Reduce \\
$4-6$ & $8-10$ & Reduce \\
Else & & \\
$7-10$ & $0-10$ &
\end{tabular}

${ }^{\mathrm{a} B o r g}$ scale 0-10.

To determine the exercise program, we used the FITT-VP (frequency, intensity, type, time, volume, and progression) principle based on American College of Sports Medicine guidelines [30]. Therefore, 3 exercise sessions were recommended, and each exercise program was be adjusted (intensity or duration) by interpreting of the training data and 
the rating of perceived pain and load every week. The recommendations are based on heart rate in training zones related to individual anaerobic threshold. The 12-week exercise program consists of 4 fixed mesocycles depending on the group (Table 4).

Table 4. Number of aerobic and anaerobic training sessions for each group.

\begin{tabular}{lllll}
\hline Group and session & $\begin{array}{l}\text { Mesocycle 1 } \\
\text { Weeks 1-3 }\end{array}$ & $\begin{array}{l}\text { Mesocycle 2 } \\
\text { Weeks 4-6 }\end{array}$ & $\begin{array}{l}\text { Mesocycle 3 } \\
\text { Weeks 7-9 }\end{array}$ & $\begin{array}{l}\text { Mesocycle 4 } \\
\text { Weeks 10-12 }\end{array}$ \\
\hline $\begin{array}{l}\text { Aerobic exercise group } \\
\quad \text { Aerobic training sessions }\end{array}$ & 3 & 3 & 3 & 3 \\
$\quad$ Anaerobic training sessions & 0 & 0 & 0 & 0 \\
Anaerobic exercise group & & & 1 & 0 \\
$\quad$ Aerobic training sessions & 3 & 2 & 2 & 3 \\
$\quad$ Anaerobic training sessions & 0 & 1 & & \\
\hline
\end{tabular}

Both intervention groups undergo the same aerobic exercise program in the first mesocycle. Afterward, differently structured mesocycles in both intervention groups are used to verify the effects of aerobic or anaerobic exercise, respectively. Each training session contains endurance exercise between 20 and 50 minutes, including a 5-minute warmup, and a 5-minute cooldown, depending on the current progression stage. Every patient can scale up, scale down, or remain on different progression stages from week 1 to week 12 according to individual training adjustments (Table 4). The aerobic exercise group performs aerobic training sessions for the whole program. In the anaerobic exercise group, more intense training sessions are progressively integrated (Table 5). For the anaerobic training sessions, we use an intermittent protocol with heart rate above the individual anaerobic threshold for 2-3 minutes per interval. The progression stages in the anaerobic exercise group range from 3 intervals ( 1 interval of 3 minutes +2 intervals of 2 minutes each) up to 8 intervals ( 8 intervals of 3 minutes each) with a 2-minute walking break between intervals, a 5-minute warmup, and a 5-minute cooldown.

To assess the effect of the intervention program, the control group (treatment as usual) will participate in voluntary exercise that is assessed using a questionnaire for habitual physical activity [31]. These participants also received a smartwatch.

We recommended that walking or running should be the main part of endurance training sessions. Moreover, we suggested performing 1 to 2 strength training session weekly or integrating specified strength training exercises into the endurance training (eg, at the end of running or walking).

We created a compilation of 10 strength exercises for major muscle groups that can be trained separately with elastic resistance bands. We recommended 3 sets with 15 repetitions per exercise each week [32]. Furthermore, the compilation includes 10 relaxation exercises, recommended for after strength training sessions. 
Table 5. Outcome parameters.

\begin{tabular}{|c|c|}
\hline Outcome & Description \\
\hline \multicolumn{2}{|l|}{ Primary outcome } \\
\hline $\mathrm{VO}_{2}$ peak $^{\mathrm{a}}$ & Using spiroergometry \\
\hline \multicolumn{2}{|l|}{ Secondary outcomes } \\
\hline $\begin{array}{l}\text { Fatigue Scale for Motor and } \\
\text { Cognitive Functions }\end{array}$ & $\begin{array}{l}\text { This scale consists of } 20 \text { items using a 5-point Likert scale, from absolutely agree to } \\
\text { absolutely disagree) to assess cognitive fatigue (10 items) and motor fatigue ( } 10 \\
\text { items). The scores for cognitive and motor fatigue are added for the sum score. A } \\
\text { cutoff value of } 43 \text { indicates mild fatigue, whereas higher values are associated with } \\
\text { moderate fatigue }(\geq 53) \text { or severe fatigue }(\geq 63)[33] \text {. }\end{array}$ \\
\hline
\end{tabular}

Beck Depression Inventory This questionnaire consists of 21 sets of statements, which are ranked in terms of severity from 0 to 3 . The sum (range $0-63$ ) indicates the severity of depression. The standardized scale is $0-8$, no depression; 9-13, minimal depression; 14-19, mild depression; 20-28, moderate depression; 29-63: severe depression [34].

Systemic Lupus Erythemato- This index consists of 24 items including clinical and laboratory variables to measure sus Disease Activity Index disease activity within the previous 10 days. The maximum score is 105 , scores $>3$ indicate a mild or moderate flare, and scores $\geq 12$ indicate a severe flare.

Disease Activity Score-28 The score indicates rheumatoid arthritis disease activity and treatment response. It is composed of 4 measures including the number of swollen or tender joints, C-reactive protein level, and patient's health assessment. A total score is calculated using the formula. Values range from 2.0 to 10, where a higher value indicates higher disease activity. The score is a valuable tool to assess the severity of joint involvement and activity in systemic lupus erythematosus.

Work Ability Index

This self-assessment questionnaire is used to assess the work ability of the patients. The questionnaire covers 6 dimensions including current work ability, as well as past 2-year estimation among others: 7-27 points indicates poor, 28-36 points indicates moderate, 37-43 points indicates good, and 44-49 points indicates very good work ability.

Revised Cutaneous Lupus This scoring system includes a score to measure the activity of skin lesions and a Erythematosus Disease Area score to measure the damage of skin lesions in patients with discoid lupus erytheand Severity Index matosus and cutaneous lupus erythematosus. The score is used as a follow-up parameter. It has been shown that scores correlate well with the physicians and patient's global assessment of disease activity.

Autoantibody titer

dsDNA $^{\text {b }}$ titer (standard value $\leq 20$ IU)

Complement level

C3c and C4 levels (standard values: C3c: 0.9-1.8 g/L; C4: 0.1-0.4 g/L)

Measurement timepoint

Week 0,12

Week $0,12,24$

Week $0,12,24$

Week $0,12,24$

Week $0,12,24$

Week $0,12,24$

Week $0,12,24$

Circulating, cell-free DNA The concentration of circulating, cell-free DNA $(\mathrm{ng} / \mathrm{mL})$ is measured before during levels and after laboratory standardized stepwise exercise test from capillary and venous blood samples. After centrifugation of the samples, the circulating cell-free DNA is determined by a direct quantitative real-time polymerase chain reaction method from plasma without previous DNA extraction [31] Compared to healthy participants patients with systemic lupus erythematosus show higher circulating cell-free DNA plasma levels.

Extracellular vesicles

The relative amount of extracellular vesicle subpopulations is analyzed using bead isolation and size exclusion chromatography followed by protein marker characterization.

Lactate levels

To estimate the lactate threshold, capillary blood samples are taken from the fingertips using end-to-end capillary with a defined volume of $20 \mu \mathrm{L}$ (sodium heparin, EKFDiagnostics $\mathrm{GmbH}$ ). Erythrocytes are hemolyzed in glucose/lactate hemolyzing solution (EKF-Diagnostics GmbH) before analysis using the Biosen S-Line (EKF-Diagnostics $\mathrm{GmbH}$ ). In this study, capillary blood samples are taken at the beginning of the test (pre), after each step of treadmill walking, as well as 3 minutes after exhaustion. All samples are quantified directly after the test. To define the anaerobic lactate acid threshold or individual anaerobic threshold the Dickhuth model (baseline $+1.5 \mathrm{mmol} / \mathrm{L}$ model) is used [35].

Ventilatory threshold

Change in ventilatory threshold after 12 weeks compared to baseline.

Week 0,12

Muscle mass will be measured in absolute mass (kilograms) including internal organs using bioelectrical impedance analysis.

Muscle mass

Change of Chair-Stand test after 12 weeks compared to baseline.

Week 0, 12, 24

Week $0,12,24$

Week 0,12

Week 0,12

Week 0,12

Week 0,12

Week 0,12 


\begin{tabular}{ll}
\hline Outcome & Description \\
\hline Borg scale & $\begin{array}{l}\text { Ratings of perceived exertion with the Borg 15-grade scale (6-20) within the last 30 Week 0, 12 } \\
\text { seconds of each stage of walking will be recorded [36]. }\end{array}$ \\
Smartwatch data & $\begin{array}{l}\text { Evaluation of the physical strain and performance during the weekly training sessions Week 0-12 } \\
\text { measured by heart rate and distance covered during running. }\end{array}$ \\
\hline
\end{tabular}

${ }^{\mathrm{a}}$ VO2 peak: peak oxygen uptake.

bdsDNA: anti-double stranded DNA.

\section{Outcomes}

\section{Primary Outcome}

The primary objective of this study is to examine changes in physical fitness in response to an internet-based exercise program with aerobic or anaerobic training protocols in patients with systemic lupus erythematosus. Therefore, the primary outcome is the change of $\mathrm{VO}_{2}$ peak (after 12 weeks in comparison to baseline).

\section{Secondary Outcomes}

The secondary outcome parameters are summarized in Table 5. This table also shows at what timepoints parameters are measured.

\section{Results}

The study was registered in May 2019 (NCT03942718). Information brochures were laid out in the rheumatology outpatient clinic of the University Medical Center Mainz for the recruitment of patients. In addition, information brochures were sent by mail to patients with systemic lupus erythematosus treated in the rheumatology outpatient clinic. Out of 40 patients who contacted us, 30 patients fulfilled the inclusion criteria and were included in the study. One patient withdrew before the first performance test and before the start of the sports program due to a fracture, and 29 patients started the study. Among the 25 patients who completed the study, no serious adverse events were reported; however, 1 patient has not yet completed the study, and 3 patients withdrew from the study. One due to repeated colds, so that regular sport was not possible, another patient had a relapse of Crohn disease during the study period, and 1 patient stated that continuing to exercise was not possible due to physical strain.

\section{Discussion}

Previous studies [20,21] indicate that exercise can lead to various benefits in patients with systemic lupus erythematosus due to an increased aerobic capacity, exercise tolerance, and quality of life as well as decreased depressive symptoms and symptoms of fatigue. These positive effects were achieved in supervised as well as unsupervised exercise programs [15,17-19,22,37,38]. In addition, it has been repeatedly discussed whether physical activity leads to an increase in lupus disease activity-an increase in autoantibodies, an increase in the consumption of complement factors, and an exacerbation of clinical symptoms such as arthralgia and myalgia. However, several recent studies $[18,20]$ have shown that physical activity is safe in patients with systemic lupus erythematosus and that there is no increase in lupus disease activity.

Nondrug therapy, especially exercise therapy, has become an important component of long-term treatment of comorbidities of systemic lupus erythematosus in recent years. Therefore, effective and efficient exercise programs need to be studied. In this study, we focus on the feasibility of an internet-based exercise program in patients with systemic lupus erythematosus. Similar concepts have already been successfully applied in other diseases such as major depressive disorder, fatty liver disease, Barrett carcinoma, cystic fibrosis, and psychiatric disorders [28,39-41].

To our knowledge, this is the first study in which exercise treatment in systemic lupus erythematosus is supervised via the internet, which has several benefits: (1) Patients with systemic lupus erythematosus can perform their individual exercise program at a self-chosen time point and do not need to participate in a presence program. Moreover, participants can fulfil their exercise program at home, which has several logistic benefits. (2) To reduce the risk of physical over- or underload, a weekly feedback protocol, which includes the rating of perceived exertion and the heart rate during the exercise sessions, is used. Based on these data, participants receive weekly-adapted exercise prescription, which allows adjustments in accordance with FITT-VP principles throughout the program. Moreover, we ensure a moderate beginning of exercise prescription to avoid injuries or dropout based on exercise overload. Other studies found a positive association between adherence, compliance, or persistence and treatment satisfaction [42] In this study, adherence can be evaluated by completed training sessions. (3) By using the platform, participants can benefit due to a chat and forum function. (4) This allows patients to communicate quickly with the sports therapist, gain insight into their own training sessions, and have the opportunity to communicate with each other. Through this exchange, there is a possibility of mutual motivation enabling social connection and lasting training bonds among participants. By using the internet to supervise the exercise program, resources are reduced, since one sports therapist can supervise participants in parallel.

Tench et al [14] showed that patients with systemic lupus erythematosus $(n=93)$ have reduced oxygen uptake in comparison to that of healthy controls $(n=41)$. Furthermore, Keyser et al [43] compared 16 healthy participants with 18 patients with systemic lupus erythematosus and found significant differences in their aerobic capacity $\left(\mathrm{VO}_{2}\right.$ peak). A meta-analysis showed an improvement of nearly $2 \mathrm{~mL} / \mathrm{kg} /$ minute of oxygen uptake after exercise treatment (12-52 weeks) [21]. Wilson et 
al [44] assume that low aerobic capacity leads to a significant restriction in daily life. Mostly all daily activities have a range of $10.5 \mathrm{~mL} / \mathrm{kg} / \mathrm{minute}$ to $17.5 \mathrm{~mL} / \mathrm{kg} /$ minute of oxygen uptake. In addition, Pinto et al [45] showed that patients with systemic lupus erythematosus have impaired aerobic capacity when compared with the aerobic capacity of controls matched by physical inactivity, age, sex, and BMI. These findings reinforce the recommendation of physical activity in systemic lupus erythematosus treatment and were recently reconfirmed by a randomized one-year physical activity program for women with systemic lupus erythematosus [46].

However, patients with systemic lupus erythematosus frequently suffer from fatigue in their daily life, so the burden of being physically active is much higher than it is for healthy patients. But when the patients are physically active, a reduction in fatigue could already be observed after a walking program of 6 weeks [22]. Thus, an individually adapted training program (based on training status and time of training) could be continuously and easily used by patients and to positively support permanent use.

Nevertheless, there are some risks in using the internet as a supervision tool. First, we presuppose that all participants have an internet device and an email account to create a user profile. Research has shown that nearly $79.5 \%$ of the population in Germany has access to an internet account [47]. Second, it could be possible that patients need the presence of a personal coach to perform the exercise sessions correctly, even to reduce the risk of injury. Therefore, precise recommendations of exercise prescription will be used and controlled. It is also possible to watch the strength exercises as videos on the internet platform. Furthermore, it already has been outlined above that systemic lupus erythematosus progress is heterogeneous which could be a critical point of this study. Patients could suffer due to health-associated problems, which could lead to an early termination of the exercise program, as they have no personal contact person on site. However, our objective is to promote a frequent contact through the platform and that the patients will not have any inhibitions and will be able to report at any time. Complaints about health problems are always passed on to the study physician so that immediate contact with the patient is possible. In this way, we hope to achieve a reduction of the risk of premature termination of the program.

A selection bias due to (1) exercise affine people and (2) internet-based motivated people could be possible. Moreover, based on etiology, it is expected that (3) mostly female participants will participate. Furthermore, (4) only participants followed by the University Medical Centre Mainz will be recruited.

This study will allow us to assess the potential for internet-based exercise program in patients with systemic lupus erythematosus by comparing our internet-based exercise program in terms of changes in levels of physical ability $\left(\mathrm{VO}_{2}\right.$ peak, anaerobic exercise group, Chair-Stand test) in the treatment groups compared to those in the treatment as usual group. Furthermore, it will allow us to study the intensities of exercise recommendations that are feasible for patients with systemic lupus erythematosus without any disadvantages in terms of disease activity.

\section{Acknowledgments}

We thank the University of Mainz for maintaining the inner-university research grant, which made it possible to pay for a doctoral student from the field of sports medicine. Additionally, this study would not have been possible without the support of the nephrology and rheumatology outpatient clinic of the University Medical Center Mainz. Finally, we thank all the patients who participated in the study.

\section{Conflicts of Interest}

None declared.

\section{References}

1. Kuhn A, Bonsmann G, Anders H, Herzer P, Tenbrock K, Schneider M. The diagnosis and treatment of systemic lupus erythematosus. Dtsch Arztebl Int 2015 Jun 19;112(25):423-432 [FREE Full text] [doi: 10.3238/arztebl.2015.0423] [Medline: 26179016]

2. Rahman A, Isenberg DA. Systemic lupus erythematosus. N Engl J Med 2008 Feb 28;358(9):929-939. [doi: 10.1056/NEJMra071297] [Medline: 18305268]

3. Brinks R, Fischer-Betz R, Sander O, Richter JG, Chehab G, Schneider M. Age-specific prevalence of diagnosed systemic lupus erythematosus in Germany 2002 and projection to 2030. Lupus 2014 Nov;23(13):1407-1411. [doi: 10.1177/0961203314540352] [Medline: 24928831]

4. Pons-Estel GJ, Alarcón GS, Scofield L, Reinlib L, Cooper GS. Understanding the epidemiology and progression of systemic lupus erythematosus. Semin Arthritis Rheum 2010 Feb;39(4):257-268 [FREE Full text] [doi:

10.1016/j.semarthrit.2008.10.007] [Medline: 19136143]

5. Aringer M, Costenbader K, Daikh D, Brinks R, Mosca M, Ramsey-Goldman R, et al. 2019 European League Against Rheumatism/American College of Rheumatology classification criteria for systemic lupus erythematosus. Ann Rheum Dis 2019 Sep;78(9):1151-1159. [doi: 10.1136/annrheumdis-2018-214819] [Medline: $\underline{31383717]}$ 
6. Fiuza-Luces C, Santos-Lozano A, Joyner M, Carrera-Bastos P, Picazo O, Zugaza JL, et al. Exercise benefits in cardiovascular disease: beyond attenuation of traditional risk factors. Nat Rev Cardiol 2018 Dec 16;15(12):731-743. [doi: 10.1038/s41569-018-0065-1] [Medline: $\underline{30115967]}$

7. Pedisic Z, Shrestha N, Kovalchik S, Stamatakis E, Liangruenrom N, Grgic J, et al. Is running associated with a lower risk of all-cause, cardiovascular and cancer mortality, and is the more the better? A systematic review and meta-analysis. Br J Sports Med 2020 Aug;54(15):898-905. [doi: 10.1136/bjsports-2018-100493] [Medline: $\underline{31685526}$ ]

8. Kaul A, Gordon C, Crow MK, Touma Z, Urowitz MB, van Vollenhoven R, et al. Systemic lupus erythematosus. Nat Rev Dis Primers 2016 Jun 16;2:16039. [doi: 10.1038/nrdp.2016.39] [Medline: 27306639]

9. Fanouriakis A, Kostopoulou M, Alunno A, Aringer M, Bajema I, Boletis JN, et al. 2019 update of the EULAR recommendations for the management of systemic lupus erythematosus. Ann Rheum Dis 2019 Jun;78(6):736-745. [doi: 10.1136/annrheumdis-2019-215089] [Medline: 30926722]

10. Jacobsen S, Petersen J, Ullman S, Junker P, Voss A, Rasmussen JM, et al. Mortality and causes of death of 513 Danish patients with systemic lupus erythematosus. Scand J Rheumatol 1999;28(2):75-80. [doi: 10.1080/030097499442522] [Medline: 10229135]

11. Fors Nieves CE, Izmirly PM. Mortality in systemic lupus erythematosus: an updated review. Curr Rheumatol Rep 2016 Apr;18(4):21. [doi: 10.1007/s11926-016-0571-2] [Medline: 26984805]

12. Schwarting A, Möckel T, Lütgendorf F, Triantafyllias K, Grella S, Boedecker S, et al. Fatigue in SLE: diagnostic and pathogenic impact of anti-N-methyl-D-aspartate receptor (NMDAR) autoantibodies. Ann Rheum Dis 2019 Sep;78(9):1226-1234. [doi: 10.1136/annrheumdis-2019-215098] [Medline: 31186256]

13. Ayán C, Martín V. Systemic lupus erythematosus and exercise. Lupus 2007;16(1):5-9. [doi: 10.1177/0961203306074795] [Medline: $\underline{17283578}$ ]

14. Tench C, Bentley D, Vleck V, McCurdie I, White P, D'Cruz D. Aerobic fitness, fatigue, and physical disability in systemic lupus erythematosus. J Rheumatol 2002 Mar;29(3):474-481. [Medline: 11908559]

15. Carvalho MRPD, Sato EI, Tebexreni AS, Heidecher RTC, Schenkman S, Neto TLB. Effects of supervised cardiovascular training program on exercise tolerance, aerobic capacity, and quality of life in patients with systemic lupus erythematosus. Arthritis Rheum 2005 Dec 15;53(6):838-844 [FREE Full text] [doi: 10.1002/art.21605] [Medline: 16342102]

16. Krupp LB, LaRocca NG, Muir J, Steinberg AD. A study of fatigue in systemic lupus erythematosus. J Rheumatol 1990 Nov;17(11):1450-1452. [Medline: 2273484]

17. Clarke-Jenssen A, Fredriksen PM, Lilleby V, Mengshoel AM. Effects of supervised aerobic exercise in patients with systemic lupus erythematosus: a pilot study. Arthritis Rheum 2005 Apr 15;53(2):308-312 [FREE Full text] [doi: 10.1002/art.21082] [Medline: 15818657]

18. Tench CM, McCarthy J, McCurdie I, White PD, D'Cruz DP. Fatigue in systemic lupus erythematosus: a randomized controlled trial of exercise. Rheumatology (Oxford) 2003 Sep;42(9):1050-1054. [doi: 10.1093/rheumatology/keg289] [Medline: 12730519]

19. Soriano-Maldonado A, Morillas-de-Laguno P, Sabio JM, Gavilán-Carrera B, Rosales-Castillo A, Montalbán-Méndez C, et al. Effects of 12-week aerobic exercise on arterial stiffness, inflammation, and cardiorespiratory fitness in women with systemic lupus erythematosus: non-randomized controlled trial. J Clin Med 2018 Nov 24;7(12) [FREE Full text] [doi: 10.3390/jcm7120477] [Medline: $\underline{30477218]}$

20. Fangtham M, Kasturi S, Bannuru RR, Nash JL, Wang C. Non-pharmacologic therapies for systemic lupus erythematosus. Lupus 2019 May;28(6):703-712 [FREE Full text] [doi: 10.1177/0961203319841435] [Medline: 30961418]

21. O'Dwyer T, Durcan L, Wilson F. Exercise and physical activity in systemic lupus erythematosus: A systematic review with meta-analyses. Semin Arthritis Rheum 2017 Oct;47(2):204-215. [doi: 10.1016/j.semarthrit.2017.04.003] [Medline: 28477898]

22. Sheikh SZ, Kaufman K, Gordon B, Hicks S, Love A, Walker J, et al. Evaluation of the self-directed format of Walk With Ease in patients with systemic lupus erythematosus: the Walk-SLE pilot study. Lupus 2019 May;28(6):764-770. [doi: 10.1177/0961203319846387] [Medline: 31042128]

23. Jones CJ, Rikli RE, Beam WC. A 30-s chair-stand test as a measure of lower body strength in community-residing older adults. Res Q Exerc Sport 1999 Jun;70(2):113-119. [doi: 10.1080/02701367.1999.10608028] [Medline: 10380242]

24. Abrahão MI, Gomiero AB, Peccin MS, Grande AJ, Trevisani VFM. Cardiovascular training vs. resistance training for improving quality of life and physical function in patients with systemic lupus erythematosus: a randomized controlled trial. Scand J Rheumatol 2016;45(3):197-201. [doi: 10.3109/03009742.2015.1094126] [Medline: 26525835]

25. Avaux M, Hoellinger P, Nieuwland-Husson S, Fraselle V, Depresseux G, Houssiau FA. Effects of two different exercise programs on chronic fatigue in lupus patients. Acta Clin Belg 2016 Dec;71(6):403-406. [doi:

10.1080/17843286.2016.1200824] [Medline: 27377292]

26. dos Reis-Neto ET, da Silva AE, Monteiro CMDC, de Camargo LM, Sato EI. Supervised physical exercise improves endothelial function in patients with systemic lupus erythematosus. Rheumatology (Oxford) 2013 Dec;52(12):2187-2195. [doi: 10.1093/rheumatology/ket283] [Medline: 23970541]

27. Tan EM, Cohen AS, Fries JF, Masi AT, McShane DJ, Rothfield NF, et al. The 1982 revised criteria for the classification of systemic lupus erythematosus. Arthritis Rheum 1982 Nov;25(11):1271-1277. [doi: 10.1002/art.1780251101] [Medline: 7138600] 
28. Pfirrmann D, Tug S, Brosteanu O, Mehdorn M, Busse M, Grimminger PP, et al. Internet-based perioperative exercise program in patients with Barrett's carcinoma scheduled for esophagectomy [iPEP - study] a prospective randomized-controlled trial. BMC Cancer 2017 Jun 14;17(1):413 [FREE Full text] [doi: 10.1186/s12885-017-3400-8] [Medline: 28615010]

29. Wonisch M, Berent R, Klicpera M, Laimer H, Marko C, Pokan R, et al. Praxisleitlinien Ergometrie. AT 2014;40(06):223-244. [doi: 10.5414/atx0947]

30. Bushman BA. Determining the I (Intensity) for a FITT-VP Aerobic Exercise Prescription. 2014;18(3):4-7. [doi: 10.1249/fit.0000000000000030]

31. Breitbach S, Tug S, Helmig S, Zahn D, Kubiak T, Michal M, et al. Direct quantification of cell-free, circulating DNA from unpurified plasma. PLoS One 2014;9(3):e87838 [FREE Full text] [doi: 10.1371/journal.pone.0087838] [Medline: 24595313]

32. Garber, Carol Ewing, Pollock M, Gaesser GM, Butcher JD, Després JP, Dishman RK, et al. American College of Sports Medicine Position Stand. The recommended quantity and quality of exercise for developing and maintaining cardiorespiratory and muscular fitness, and flexibility in healthy adults. Med Sci Sports Exerc 1998 Jun;30(6):975-991. [Medline: 9624661$]$

33. Penner IK, Raselli C, Stöcklin M, Opwis K, Kappos L, Calabrese P. The Fatigue Scale for Motor and Cognitive Functions (FSMC): validation of a new instrument to assess multiple sclerosis-related fatigue. Mult Scler 2009 Dec;15(12):1509-1517. [doi: 10.1177/1352458509348519] [Medline: 19995840 ]

34. Reynolds WM, Gould JW. A psychometric investigation of the standard and short form Beck Depression Inventory. J Consult Clin Psychol 1981 Apr;49(2):306-307. [doi: 10.1037//0022-006x.49.2.306] [Medline: 7217503]

35. Westhoff M. Positionspapier der AG/Spiroergometrie zu ventilatorischen und Laktatschwellen. Dtsch Medizinische Wochenzeitschrift 2010.

36. Borg GA. Psychophysical bases of perceived exertion. Med Sci Sports Exerc 1982;14(5):377-381. [Medline: 7154893$]$

37. Robb-Nicholson LC, Daltroy L, Eaton H, Gall V, Wright E, Hartley LH, et al. Effects of aerobic conditioning in lupus fatigue: a pilot study. Br J Rheumatol 1989 Dec;28(6):500-505. [doi: 10.1093/rheumatology/28.6.500] [Medline: 2590802]

38. Yuen HK, Holthaus K, Kamen DL, Sword DO, Breland HL. Using Wii Fit to reduce fatigue among African American women with systemic lupus erythematosus: a pilot study. Lupus 2011 Oct;20(12):1293-1299 [FREE Full text] [doi: 10.1177/0961203311412098] [Medline: 21700656]

39. Huber Y, Pfirrmann D, Gebhardt I, Labenz C, Gehrke N, Straub BK, et al. Improvement of non-invasive markers of NAFLD from an individualised, web-based exercise program. Aliment Pharmacol Ther 2019 Oct;50(8):930-939. [doi: 10.1111/apt.15427] [Medline: 31342533]

40. Pfirrmann D, Haller N, Huber Y, Jung P, Lieb K, Gockel I, et al. Applicability of a web-based, individualized exercise intervention in patients with liver disease, cystic fibrosis, esophageal cancer, and psychiatric disorders: process evaluation of 4 ongoing clinical trials. JMIR Res Protoc 2018 May 22;7(5):e106 [FREE Full text] [doi: 10.2196/resprot.8607] [Medline: 29789277]

41. Haller N, Lorenz S, Pfirrmann D, Koch C, Lieb K, Dettweiler U, et al. Individualized web-based exercise for the treatment of depression: randomized controlled trial. JMIR Ment Health 2018 Oct 12;5(4):e10698 [FREE Full text] [doi: 10.2196/10698] [Medline: 30314962]

42. Barbosa CD, Balp M, Kulich K, Germain N, Rofail D. A literature review to explore the link between treatment satisfaction and adherence, compliance, and persistence. Patient Prefer Adherence 2012;6:39-48 [FREE Full text] [doi: 10.2147/PPA.S24752] [Medline: 22272068]

43. Keyser RE, Rus V, Cade WT, Kalappa N, Flores RH, Handwerger BS. Evidence for aerobic insufficiency in women with systemic lupus erythematosus. Arthritis Rheum 2003 Feb 15;49(1):16-22 [FREE Full text] [doi: 10.1002/art.10926] [Medline: $\underline{12579589]}$

44. Ainsworth BE, Haskell WL, Whitt MC, Irwin ML, Swartz AM, Strath SJ, et al. Compendium of physical activities: an update of activity codes and MET intensities. Med Sci Sports Exerc 2000 Sep;32(9 Suppl):S498-S504. [doi: 10.1097/00005768-200009001-00009] [Medline: 10993420]

45. Pinto AJ, Miyake CNH, Benatti FB, Silva CA, Sallum AME, Borba E, et al. Reduced aerobic capacity and quality of life in physically inactive patients with systemic lupus erythematosus with mild or inactive disease. Arthritis Care Res (Hoboken) 2016 Dec;68(12):1780-1786 [FREE Full text] [doi: 10.1002/acr.22905] [Medline: 27058995]

46. Boström C, Elfving B, Dupré B, Opava CH, Lundberg IE, Jansson E. Effects of a one-year physical activity programme for women with systemic lupus erythematosus - a randomized controlled study. Lupus 2016 May;25(6):602-616. [doi: 10.1177/0961203315622817] [Medline: 26768748]

47. Koch W, Frees B. Internetnutzung: Frequenz und Vielfalt nehmen in allen Altersgruppen zu. Media Perspektiven 2015 Sep:366-377 [FREE Full text]
Abbreviations
BMI: body mass index
ECG: electrocardiography
FITT-VP: frequency, intensity, type, time, volume, and progression
VO2 peak: peak oxygen uptake 


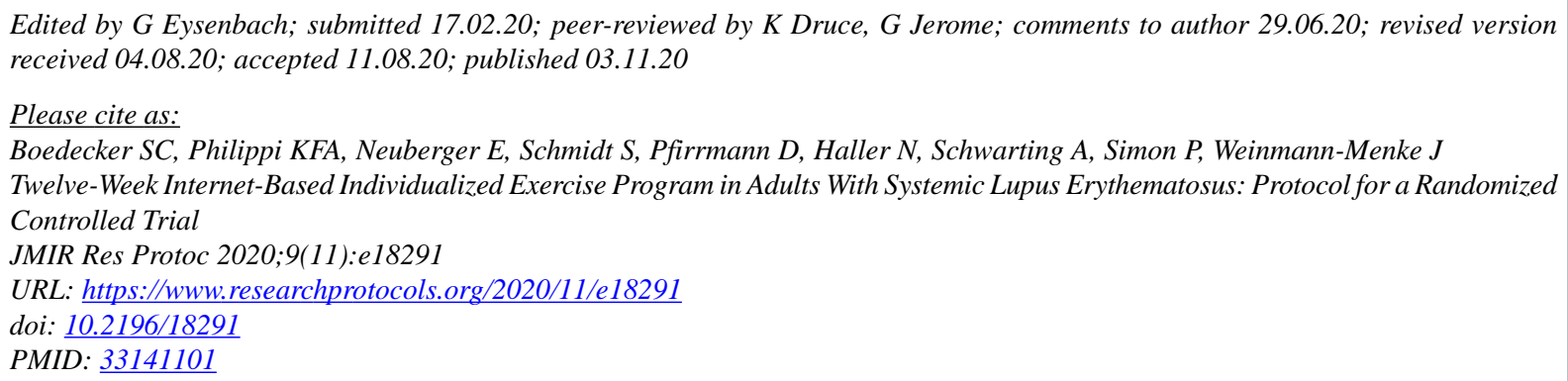

(CSimone Cosima Boedecker, Keito Finn Akanby Philippi, Elmo Neuberger, Sebastian Schmidt, Daniel Pfirrmann, Nils Haller, Andreas Schwarting, Perikles Simon, Julia Weinmann-Menke. Originally published in JMIR Research Protocols (http://www.researchprotocols.org), 03.11.2020. This is an open-access article distributed under the terms of the Creative Commons Attribution License (https://creativecommons.org/licenses/by/4.0/), which permits unrestricted use, distribution, and reproduction in any medium, provided the original work, first published in JMIR Research Protocols, is properly cited. The complete bibliographic information, a link to the original publication on http://www.researchprotocols.org, as well as this copyright and license information must be included. 